Kansas State University Libraries

New Prairie Press

\title{
SPATIAL ANALYSIS OF YIELD TRIALS USING SEPARABLE ARIMA PROCESSES
}

\author{
M. O. Grondona \\ J. Crossa \\ P. N. Fox \\ W. H. Pfeiffer
}

See next page for additional authors

Follow this and additional works at: https://newprairiepress.org/agstatconference

Part of the Agriculture Commons, and the Applied Statistics Commons

\section{(c) (1) $9 \Theta$}

This work is licensed under a Creative Commons Attribution-Noncommercial-No Derivative Works 4.0 License.

\section{Recommended Citation}

Grondona, M. O.; Crossa, J.; Fox, P. N.; and Pfeiffer, W. H. (1993). "SPATIAL ANALYSIS OF YIELD TRIALS USING SEPARABLE ARIMA PROCESSES," Conference on Applied Statistics in Agriculture. https://doi.org/ $10.4148 / 2475-7772.1373$

This is brought to you for free and open access by the Conferences at New Prairie Press. It has been accepted for inclusion in Conference on Applied Statistics in Agriculture by an authorized administrator of New Prairie Press. For more information, please contact cads@k-state.edu. 
Author Information

M. O. Grondona, J. Crossa, P. N. Fox, and W. H. Pfeiffer

This is available at New Prairie Press: https://newprairiepress.org/agstatconference/1993/proceedings/7 


\section{SPATIAL ANALYSIS OF YIELD TRIALS USING SEPARABLE ARIMA PROCESSES}

M.O. Grondona, Instituto de Clima y Agua, INTA, Argentina J. Crossa, P.N. Fox and W.H. Pfeiffer, CIMMYT, Mexico

\section{ABSTRACT}

Spatial analysis procedures based on one-dimensional and two-dimensional (separable) ARIMA (Auto Regressive Integrated Moving Average) processes were used to analyze several yield trials. Two criteria were used to determine the best spatial model: 1) standard error of the treatment difference (SED) and 2) mean squared error (MSE) of prediction based on a cross-validation approach. It is found that spatial models with two-dimensional exponential covariance functions are frequently the best models regarding SED and MSE. Differenced models are frequently the best models regarding SED and the worst with respect to MSE.

\section{INTRODUCTION}

The main objective of variety trials is to obtain precise estimates of differences in yield. However, spatial variability due to fertility gradients, environmental factors, etc., may cause: 1) serious bias in the estimation of treatment effects and 2) inflation of the residual variation. Thus it is important to reduce residual variation not accounted for by the treatment effects. Residual variation can be reduced through the use of appropriate experimental designs, nearest neighbor approach, and/or spatial methods of analysis.

Recently, several models have been proposed to account for spatial variability (Besag and Kempton, 1986; Gleeson and Cullis, 1987; Williams, 1986; Martin, 1990; Zimmerman and Harvilie, 1991; Grondona and Cressie, 1991; Cullis and Gleeson; 1991). Spatial variation is modeled by including two main components: 1) the "global trend", which is modeled through the mean structure, and 2) the "local trend", which is modeled through a random spatially-correlated structure.

One problem with the spatial approach is the inadequate diagnostics to select the best models. One measure for comparing different models is the average variance of the difference between pairs of varieties. To compute this measure, the parameter vector $\theta$ of the spatial-covariance function should be known. The customary procedures are obtained by substituting an estimator $\hat{\theta}$ for $\theta$ in the 
expression for the variance of the treatment difference. This measure relies on assumptions regarding the covariance structure, and underestimates the true average variance of the pairwise treatment differences, since the uncertainty in the estimation of $\theta$ is not taken into account. A less dependent measurement of the model's adequacy is obtained with the cross-validation approach (Stone, 1974; Geisser, 1975), where each observation in turn is considered missing and predicted for the remaining ones.

The objectives of this article are: 1) to analyze sets of variety trials using several spatial models with the separable error structure proposed by Cullis and Gleeson (1991) and 2) to describe and use a cross-validation approach for selecting the best spatial models.

\section{THE SPATIAL MODELS}

The general form of the two-dimensional model proposed by Cullis and Gleeson (1991) comprises terms for: 1) fixed effects (treatments, covariates, etc.), 2) random effects (test lines in unreplicated trials, blocks in incomplete block analysis with recovery of inter-block information, 3) global trend effects or large-scale variation (row and column effects, polynomial trend), 4) local trend effects or smooth small-scale variation (the spatially correlated random component), and 5) error effect, which is the random component representing error measurements and is assumed to be identically and independently distributed.

Assuming that the experimental trial has $r$ rows and $c$ columns, the spatial models used in this paper can be represented by the following general linear model:

\section{$Y=D \alpha+Z \Gamma+W+e$}

where $Y$ represents the vector response, sorted by columns and rows within columns; $\alpha$ represents the treatment effects (varieties); $D$ is the design matrix for the treatments; $\Gamma$ represents the global trend variation, e.g., block effects, polynomial trend, etc, $; \mathbf{Z}$ is the design matrix for the global trend; $\mathbf{w}$ represents the smooth local trend variation, modeled as a spatially dependent random vector with a mean of zero; e is a vector of random residuals which are identically and independently distributed with variance $\mathbf{I} \sigma^{2}$. The vector $\Gamma$ will usually be considered as a fixed effect, except in the incomplete block analysis with recovery of inter-block information where the block effect $\Gamma$ is assumed random.

Adding the assumption of normality, the parameters of the covariance structure are estimated by REML.

The local trend component is modeled as a separable ARIMA process, i.e., separate ARIMA processes are assumed in the row and column directions. ARIMA processes are characterized by 
three parameters: $p$, the order of autoregression; $d$, the order of differencing, and $q$, the order of the moving average; they are denoted as ARIMA ( $p, d, q)$. Low order processes (o or 1 ) will usually be sufficient to represent the local trend component w. Commonly used ARIMA processes are: $\operatorname{ARIMA}(1,0,0)$ (exponential decreasing correlation structure), $\operatorname{ARIMA}(0,1,0)$ (differenced observations are independent), $\operatorname{ARIMA}(0,0,1)$ (after differencing, just neighbor plots are correlated) and $\operatorname{ARIMA}(0,1,1)$ (just correlation between neighbor differenced observations).

The 22 spatial models fitted in this paper are special cases of (1); every model included a fixed variety effect component $D \alpha$. The classical analysis approach is considered by including the following models: 1) complete block design (CB), 2) incomplete block with blocks as fixed effects (IB-F) and 3) incomplete block with blocks as random effects (IB-R). The remaining 19 models are presented in Table 1.

\section{CROSS-VALIDATION}

We use cross-validation in a way similar to its application in geostatistics, where a variogram model is fitted (Cressie, 1991). Assume $\operatorname{var}(\mathbf{Y})=\Sigma(\theta)$ and let $\hat{\theta}$ be the fitted covariance parameter obtained using all the data. Cross-validation involves deleting each plot observation and spatially predicting ("kriging") it with the vector of $n-1$ remaining observations $\mathbf{Y}_{n-1}$, based on the fitted covariance parameter $\theta$. Consider for simplicity that $Y_{n}$ is the deleted or "missing" observation, then the best linear unbiased "spatial" predictor (BLUP) of $Y_{n}$, denoted $\hat{Y}_{n}=\lambda^{\prime} Y_{n-1}$, is obtained by minimizing $E\left(Y_{n}-\lambda^{\prime} Y_{n-1}\right)^{2}$ subject to the unbiased condition

$E\left(Y_{n}-\lambda^{\prime} Y_{n-1}\right)=0$. Denote with $X^{\prime}=\left[X_{n-1}^{\prime} X_{n}\right]$ the incidence matrix associated with all fixed effects, e.g., $\mathbf{X}=[\mathbf{D} \mathbf{Z}]$, where $\mathrm{X}_{\mathrm{n}-1}$ is the matrix containing the first $n-1$ rows of $x$ and $x^{\prime}{ }_{n}$ is the last row of $\mathbf{x}$. Assume, without loss of generality, that $x$ is the full column rank. Then the ("universal") kriging equations are obtained by differentiating

$\Psi(\lambda, m)=E\left(\lambda ' Y_{n-1}-Y_{n}\right)^{2}+m^{\prime} E\left(\lambda ' Y_{n-1}-Y_{n}\right)$ with respect to $\lambda$ and $m$ (Cressie, 1991). Equating to zero the resulting system of equations the kriging predictor is given by $\lambda^{\prime} \mathbf{Y}_{n-1}$ with

$$
\lambda^{\prime}=\left\{\sigma_{n}+X_{n-1}\left(X_{n-1}^{\prime} \Sigma_{n-1}^{-1} X_{n-1}\right)^{-1}\left(x_{n}-X_{z-1}^{\prime} \Sigma_{n-1}^{-1} \sigma_{n}\right)\right\} \Sigma_{n-1}^{-1}
$$

where $\sigma_{n}=\sigma_{n}(\theta)=\operatorname{Cov}\left(Y_{n-1}, Y_{n}\right)$ and $\Sigma_{n-1}=\Sigma_{n-1}(\theta)=\operatorname{var}\left(Y_{n-1}\right)$.

Under the integrated or differenced local trend models, i.e., $\mathrm{w}$ is an ARIMA $\left(\mathrm{p}_{1}, 1, \mathrm{q}_{1}\right)$ XARIMA $\left(\mathrm{p}_{2}, 1, \mathrm{q}_{2}\right)$ process, developing the kriging equations poses some complications since the 
covariance is defined in terms of the increment of the observations and not of the vector $Y$. The kriging equations could be derived by assuming $\left\{Y_{i}: i=1, \ldots, n\right\}$ as an intrinsic random process with generalized covariance matrix $k$. In practice, there is no problem with using the kriging equations since this is equivalent to fitting a dummy covariate for each missing observation and computing its generalized least squares estimator using the fitted covariance parameter $\theta$ (Green, 1985).

\section{EXPERIMENTAL DATA}

Four sets of CIMMYT's triticale and wheat yield trials, described below, were analyzed using the spatial model presented in section 2 .

Set 1. 1990/91 Triticale Preliminary Yield Trials conducted at cd. Obregon, Mexico (PYTI)

Eighteen adjacent trials, each with 56 entries and the same two check lines arranged in a resolvable incomplete block design with two superblocks were analyzed. The entries had two replicates and the checks were replicated eight times each. The experimental layout is 16 rows and 8 columns; incomplete blocks correspond to rows.

Set 2. 1990/91 Preliminary Yield Trials planted in Huamantla, Mexico (PYT2)

This set includes four adjacent trials, each having 56 entries replicated three times and one check replicated 24 times. The experimental design for each trial is a resolvable incomplete block design with eight plots in each block. The layout consists of 24 rows and 8 columns; incomplete blocks correspond to rows.

Set 3. 1990/91 International Triticale Yield Nurseries (ITYN-22)

Six trials from the international triticale nurseries were analyzed. Each trial had 25 entries in an $\alpha$-lattice design with three replicates and incomplete blocks of five plots each. Layout differs among experiments and is determined by individual cooperators. 
Set 4. 1990/91 Elite Durum Yield Trials (EDYT-20)

Seven trials from the durum wheat international nurseries were analyzed. The experimental design for each trial is an $\alpha-$ lattice with 30 entries, incomplete blocks of five plots and three replicates. As in the ITYN trials, the layout varies from trial to trial.

\section{RESULTS OF SPATIAL ANALYSES AND THE CROSS-VALIDATION PROCEDURE ON SEVERAL VARIETY TRIALS}

Two criteria were used to determine the best spatial models. The first criterion is the mean squared error (MSE) obtained from the cross-validation procedure. The average predicted error sums of squares, called PRESS in the linear regression approach (Allen, 1971), measures the fit of the predicted value of the model to the corresponding observed value

$$
M S E=\frac{1}{n} \sum_{i=1}^{n}\left(Y_{i}-\hat{Y}_{i}\right)^{2}
$$

The relative efficiency of the model in terms of the MSE is the ratio of MSE for the complete block model (CB) over the MSE for the model of interest (MSE-RE).

The other criterion used to determine the best spatial model was the relative efficiency based on the standard error of the treatment difference (SED). The average standard error (SED of the pairwise treatment difference) is

$$
S E D=\sqrt{\frac{1}{t(t-1)} \sum_{i=1}^{t} \sum_{j=1}^{t} \operatorname{var}\left(\boldsymbol{\alpha}_{i}-\boldsymbol{\alpha}_{j}\right)}
$$

The relative efficiency of the model in terms of the SED is calculated as the squared ratio of the SED for the complete block model (CB) over the SED for the model of interest (SED$R E)$.

Models with one-dimensional first order differences in the row or column direction (models 9 and 14, respectively) or two-dimensional first order differences in the row and column directions (model 21) assume no plot variance; therefore, they are considered unreasonable (Gilmour, 1992). However, first order difference models seem to be valid in a randomization framework (Besag and Kempton, 1986; Zimmerman and Harville, 1991). 
The TWoD software (Gilmour, 1992) was used to calculate the average variance of pairwise differences of entries for each of the 22 models and SAS IML was used to compute the mean squared error of prediction.

In Tables 2 to 5, the "best" model, in terms of the average predicted error sums of squares (MSE), the standard error of differences including all models (SED (a)), and the standard error of differences excluding models 9, 14, and 21 (SED (b)), is presented for every trial. The second and third columns of Tables 2-5 present the SED-RE and MSE-RE of the incomplete block analysis with recovery of interblock information (IB-R). The tables show the SED-RE and the average predicted error sums of squares efficiency (MSE-RE). The latter is computed as the ratio of the CB'S MSE, defined in (4), over the model's MSE.

Tables 2-5 show the superiority, in terms of the SED and the MSE criteria, of spatial models compared with complete and incomplete block models. Considering the SED (a) criterion, first-order difference models $(9,14$ and 21) usually give the smallest values ( 20 out of 35 times). The most frequent ( 16 times) and best (with respect to SED-RE) is model 14, ARIMA $(0,1,0)$ in the row direction (Fig. 1), with average SED-RE and MSE-RE of 1.55 and 1.09 , respectively (Table 6). The next most frequent ( 9 times) SED model is $17,2 \mathrm{~d} A R(1)$ (Fig. 1) with an average SED-RE and MSE-RE of 2.03 and 2.23 , respectively (Table 6). When models 9, 14, and 21 are omitted from the analysis, 2d AR(1) (model 17) is the best SED (b) model in 21 trials (Fig. 1) with average SED-RE and MSE-RE of 1.75 and 1.70, respectively (Table 6). The next most frequent model is Cols+AR(1)C (model 12) with the smallest SED value in five trials and an average SED-RE of 1.70 .

When models are chosen by cross-validation (MSE), the first-order difference models $(9,14$, and 21) never yield the minimum average prediction sum of squares (Fig. 1). Twodimensional $A R(1)$ (model 17) is the model that most frequently (14 times) (Fig. 1) achieves the smallest MSE value with an average SED-RE and MSE-RE of 1.70 and 1.64, respectively (Tables. 6). The next most frequent (5 times) best model is Cols+AR(1) (Fig. 1) with average SED-RE and MSE-RE of 1.71 and 2.60 , respectively. These results are consistent with results obtained by Zimmerman and Harville (1991) from a randomization study of uniformity trials. The methods that accounted for two-dimensional spatial correlation were generally the most accurate.

Modeling the small-scale variation $w$ as $\operatorname{ARIMA}(0,1,0)$ processes in one dimension (models 9 and 14 ) or in two dimensions (model 21) produces minimum MSE-RE values but large SED-RE values (Fig. 1). However, modeling the small-scale variation as $2 \mathrm{~d} A R(1)$ produces large values for both SED-RE and MSE-RE (Table 6). 


\section{CONCLUSIONS}

The spatial approach is more successful in reducing residual variation than the classic design approach with independent observations. Results also indicate that models selected based solely on the average variance of pairwise differences frequently did not perform satisfactorily under the cross-validation criterion. Modeling the small-scale variation component as $\operatorname{ARIMA}(0,1,0)$ processes in one or two dimensions frequently yields minimum MSE-RE values and large SED-RE values. The results presented here are consistent with those of previous studies in which the two-dimensional spatial approach has proved superior to the one-dimensional approach.

\section{Acknowledgments}

The authors thank the numerous investigators and helpers who cooperated in the national research programs that carried out the trials.

\section{REFERENCES}

Allen, D. M. (1971). The prediction sum of squares as a criterion for selecting predictor variables. Technical Report No. 23, Department of statistics, University of Kentucky, Lexington, KY.

Besag, J. E. and Kempton, R. A. (1986). Statistical analysis of field experiments using neighbouring plots. Biometrics 42, 231-251

Cressie, N. (1991). Statistics for Spatial Data. John Wiley \& Sons: New York.

Cullis, B. R. and Gleeson, A. C. (1991). Spatial analysis of field experiments - An extension to two dimension. Biometrics 47, 1449-1460.

Geisser, S. (1975). The predictive sample reuse method with applications. Journal of the American Statistical Association 70, 320-328.

Gilmour, A.R. 1992. TwoD a program to fit a mixed linear model with two dimensional spatial adjusment for local trend. NWS Agriculture Biometric Bulletin No. 1. NWS Agriculture Research Centre, Tamworth, Australia.

Gleeson, A. C. and Cullis, B. R. (1987). Residual maximum likelihood (REML) estimation of a neighbour model for field experiments. Biometrics 43, 277-288.

Green, P. (1985). Linear models for field trials, smoothing and cross-validation. Biometrika 72, 527-537. 
Grondona, M. O. and Cressie, N. (1991). Using spatial considerations in the analysis of field experiments. Technometrics 33, 381-391.

Martin, R. J. (1990). The use of time-series models and methods in the analysis of agricultural field trials. Communications in statistics. Theory and Methods 19, 55-81.

Stone, M. (1974). Cross-validatory choice and assessment of statistical predictions. Journal of the Royal Statistical society, series B 36, 111-113.

Williams, E. R. (1986). A neigbour model for field experiments. Biometrika 73, 279-287.

Zimmerman, D. L. and Harville, D. A. (1991). A random field approach to the analysis of field-plot experiments and other spatial experiments. Biometrics 47 , $223-239$. 
Table 1. Fitting spatial models (non-classical).

\begin{tabular}{|c|c|c|c|c|c|}
\hline \multirow{2}{*}{\multicolumn{2}{|c|}{ Model }} & \multicolumn{4}{|c|}{ Trend } \\
\hline & & \multicolumn{2}{|c|}{ Global $\left({ }^{*}\right)$} & \multicolumn{2}{|c|}{ Local } \\
\hline & & \multirow{2}{*}{ Row } & \multirow{2}{*}{ Col } & \multirow{2}{*}{$\frac{\text { Row }}{\operatorname{ARIMA}\left(\mathrm{p}_{1}, \mathrm{~d}_{1}, \mathrm{q}_{1}\right)}$} & \multirow{2}{*}{$\frac{\text { Col. }}{\operatorname{ARIMA}\left(\mathrm{p}_{2}, \mathrm{~d}_{2}, \mathrm{q}_{2}\right)}$} \\
\hline N & Description & & & & \\
\hline 4 & Rows & $x$ & & & \\
\hline 5 & $A R(1) R$ & & & $(1,0,0)$ & \\
\hline 6 & Rows + $A R(1) R$ & $x$ & & $(1,0,0)$ & \\
\hline 7 & Cols & & $x$ & & \\
\hline 8 & Cols + AR(1)R & & $x$ & $(1,0,0)$ & \\
\hline 9 & Diff. Cols & & & & $(0,1,0)$ \\
\hline 10 & Diff. Cols + MA(1)C & & & & $(0,1,1)$ \\
\hline 11 & $A R(1) C$ & & & & $(1,0,0)$ \\
\hline 12 & Cols + AR(1)C & & $x$ & & $(1,0,0)$ \\
\hline 13 & Rows $+A R(1) C$ & $x$ & & & $(1,0,0)$ \\
\hline 14 & Diff. Rows & & & $(0,1,0)$ & \\
\hline 15 & Diff. Rows + MA(1)R & & & $(0,1,1)$ & \\
\hline 16 & Rows\&Cols & $x$ & $x$ & & \\
\hline 17 & $2 d A R(1)$ & & & $(1,0,0)$ & $(1,0,0)$ \\
\hline 18 & Rows\&Cols $+A R(1) R$ & $x$ & $x$ & $(1,0,0)$ & \\
\hline 19 & Rows\&Cols $+A R(1) C$ & $x$ & $x$ & & $(1,0,0)$ \\
\hline 20 & Rows\&Cols $+2 d$ AR( 1$)$ & $x$ & $x$ & $(1,0,0)$ & $(1,0,0)$ \\
\hline 21 & Diff. Rows\&Cols & & & $(0,1,0)$ & $(0,1,0)$ \\
\hline 22 & Diff. Rows\&Cols $+2 d M A(1)$ & & & $(0,1,1)$ & $(0,1,1)$ \\
\hline
\end{tabular}

$\left.{ }^{*}\right)$ The $X$ indicates that the corresponding main effect is fitted. 
Table 2. PYT1:Best Models using the MSE and SED criteria

\begin{tabular}{|c|c|c|c|c|c|c|c|c|c|c|c|}
\hline \multirow{2}{*}{$\begin{array}{c}\text { Tri- } \\
\text { al }\end{array}$} & \multicolumn{2}{|c|}{ IB-R } & \multicolumn{3}{|c|}{ MSE } & \multicolumn{3}{|c|}{$\operatorname{SED}(a)$} & \multicolumn{3}{|c|}{ SED (b) } \\
\hline & $\begin{array}{l}\text { SED } \\
\text {-RE }\end{array}$ & $\begin{array}{c}\text { MSE } \\
-R E\end{array}$ & $\begin{array}{c}\text { Mo- } \\
\text { del }\end{array}$ & $\begin{array}{c}\text { SED } \\
\text {-RE }\end{array}$ & $\begin{array}{c}\text { MSE } \\
-R E\end{array}$ & $\begin{array}{c}\text { Mo- } \\
\text { del }\end{array}$ & $\begin{array}{c}\text { SED } \\
-R E\end{array}$ & $\begin{array}{c}\text { MSE } \\
-R E\end{array}$ & $\begin{array}{l}\text { Mo- } \\
\text { del }\end{array}$ & $\begin{array}{l}\text { SED } \\
-R E\end{array}$ & $\begin{array}{c}\text { MSE } \\
-R E\end{array}$ \\
\hline 1 & 1.09 & 1.12 & 20 & 2.28 & 2.89 & 17 & 3.27 & 2.73 & 17 & 3.27 & 2.73 \\
\hline 2 & 1.07 & 1.07 & 17 & 1.14 & 1.17 & 17 & 1.14 & 1.17 & 17 & 1.14 & 1.17 \\
\hline 3 & 0.98 & 1.02 & 11 & 1.07 & 1.02 & 11 & 1.07 & 1.02 & 11 & 1.07 & 1.02 \\
\hline 4 & 1.01 & 1.03 & 15 & 1.48 & 1.54 & 14 & 1.61 & 1.03 & 13 & 1.48 & 1.54 \\
\hline 5 & 0.96 & 1.00 & 13 & 0.87 & 1.12 & 14 & 1.09 & 0.67 & 1 & 1.00 & 1.00 \\
\hline 6 & 1.12 & 1.13 & 5 & 1.26 & 1.30 & 17 & 1.39 & 1.25 & 17 & 1.39 & 1.25 \\
\hline 7 & 1.15 & 1.24 & 6 & 1.02 & 1.31 & 14 & 1.53 & 1.31 & 7 & 1.28 & 1.29 \\
\hline 8 & 1.22 & 1.42 & 13 & 1.13 & 1.46 & 3 & 1.22 & 1.42 & 3 & 1.22 & 1.42 \\
\hline 9 & 1.25 & 1.41 & 3 & 1.25 & 1.41 & 17 & 1.34 & 1.39 & 17 & 1.34 & 1.39 \\
\hline 10 & 0.82 & 0.84 & 17 & 3.63 & 3.85 & 17 & 3.63 & 3.85 & 17 & 3.63 & 3.85 \\
\hline 11 & 0.97 & 0.99 & 15 & 1.22 & 1.26 & 14 & 1.27 & 0.91 & 17 & 1.22 & 1.17 \\
\hline 12 & 0.78 & 0.79 & 1 & 1.00 & 1.00 & 14 & 1.06 & 0.62 & 1 & 1.00 & 1.00 \\
\hline 13 & 0.95 & 0.96 & 15 & 1.30 & 1.40 & 14 & 1.56 & 1.23 & 17 & 1.43 & 1.34 \\
\hline 14 & 0.95 & 1.05 & 18 & 1.25 & 1.88 & 12 & 1.49 & 1.38 & 12 & 1.49 & 1.38 \\
\hline 15 & 1.14 & 1.17 & 17 & 1.62 & 1.50 & 17 & 1.62 & 1.50 & 17 & 1.62 & 1.50 \\
\hline 16 & 0.98 & 0.99 & 17 & 1.30 & 1.23 & 17 & 1.30 & 1.23 & 17 & 1.30 & 1.23 \\
\hline 17 & 0.95 & 0.94 & 12 & 1.18 & 1.20 & 14 & 1.25 & 0.82 & 17 & 1.18 & 1.08 \\
\hline 18 & 0.84 & 0.79 & 12 & 1.58 & 1.47 & 14 & 1.67 & 1.08 & 12 & 1.58 & 1.47 \\
\hline Avg & 1.01 & 1.05 & & 1.42 & 1.56 & & 1.58 & 1.37 & & 1.53 & 1.49 \\
\hline
\end{tabular}

(a) Including all models

(b) Excluding models 9, 14 and 21 
Table 3. PYT2: Best models using the MSE and SED criteria

\begin{tabular}{|c|c|c|c|c|c|c|c|c|c|c|c|}
\hline \multirow{2}{*}{$\begin{array}{l}\text { Tri } \\
\text {-al }\end{array}$} & \multicolumn{2}{|c|}{ IB-R } & \multicolumn{3}{|c|}{ MSE } & \multicolumn{3}{|c|}{ SED (a) } & \multicolumn{3}{|c|}{ SED (b) } \\
\hline & $\begin{array}{l}\text { SED } \\
-R E\end{array}$ & $\begin{array}{l}\text { MSE } \\
-R E\end{array}$ & $\begin{array}{l}\text { Mo- } \\
\text { del }\end{array}$ & $\begin{array}{l}\text { SED } \\
-R E\end{array}$ & $\begin{array}{l}M S E \\
-R E\end{array}$ & $\begin{array}{l}\text { Mo- } \\
\text { del }\end{array}$ & $\begin{array}{l}\text { SED } \\
-R E\end{array}$ & $\begin{array}{l}M S E \\
-R E\end{array}$ & $\begin{array}{l}\text { Mo- } \\
\text { del }\end{array}$ & $\begin{array}{l}\text { SED } \\
-R E\end{array}$ & $\begin{array}{c}M S E \\
-R E\end{array}$ \\
\hline 1 & 0.93 & 0.93 & 17 & 1.90 & 1.69 & 14 & 2.11 & 1.45 & 17 & 1.90 & 1.69 \\
\hline 2 & 0.90 & 0.96 & 22 & 0.76 & 1.24 & 14 & 1.30 & 0.88 & 17 & 1.23 & 1.19 \\
\hline 3 & 0.89 & 0.97 & 20 & 1.37 & 2.05 & 14 & 2.53 & 1.98 & 17 & 2.35 & 2.04 \\
\hline 4 & 0.96 & 0.98 & 17 & 2.69 & 2.61 & 14 & 2.70 & 2.16 & 17 & 2.69 & 2.61 \\
\hline Avg & 0.92 & 0.96 & & 1.68 & 1.90 & & 2.16 & 1.62 & & 2.04 & 1.88 \\
\hline
\end{tabular}

(a) Including all models

(b) Excluding models 9, 14 and 21

Table 4. ITYN-22: Best models using the MSE and SED criteria

\begin{tabular}{|c|c|c|c|c|c|c|c|c|c|c|c|}
\hline \multirow{2}{*}{$\begin{array}{l}\text { Tri- } \\
\text { al }\end{array}$} & \multicolumn{2}{|c|}{ IB-R } & \multicolumn{3}{|c|}{ MSE } & \multicolumn{3}{|c|}{ SED (a) } & \multicolumn{3}{|c|}{ SED (b) } \\
\hline & $\begin{array}{l}\text { SED } \\
-R E\end{array}$ & $\begin{array}{l}\text { MSE } \\
-R E\end{array}$ & $\begin{array}{l}\text { Mo- } \\
\text { del }\end{array}$ & $\begin{array}{l}\text { SED } \\
\text {-RE }\end{array}$ & $\begin{array}{l}\text { MSE } \\
-R E\end{array}$ & $\begin{array}{l}\text { Mo- } \\
\text { del }\end{array}$ & $\begin{array}{l}\text { SED } \\
\text {-RE }\end{array}$ & $\begin{array}{l}\text { MSE } \\
-R E\end{array}$ & $\begin{array}{l}\text { Mo- } \\
\text { del }\end{array}$ & $\begin{array}{l}\text { SED } \\
-R E\end{array}$ & $\begin{array}{c}\text { MSE } \\
-R E\end{array}$ \\
\hline 1 & 1.03 & 1.06 & 17 & 1.08 & 1.10 & 14 & 1.13 & 0.68 & 17 & 1.08 & 1.10 \\
\hline 2 & 1.38 & 3.73 & 12 & 1.59 & 6.15 & 17 & 1.68 & 4.65 & 17 & 1.68 & 4.65 \\
\hline 3 & 0.99 & 0.90 & 17 & 1.19 & 1.12 & 14 & 1.34 & 0.99 & 17 & 1.19 & 1.12 \\
\hline 4 & 0.92 & 0.83 & 17 & 2.94 & 2.38 & 17 & 2.94 & 2.38 & 17 & 2.94 & 2.38 \\
\hline 5 & 1.43 & 1.31 & 20 & 1.35 & 1.34 & 9 & 1.54 & 1.00 & 3 & 1.43 & 1.31 \\
\hline 6 & 1.28 & 1.17 & 17 & 1.81 & 1.79 & 21 & 2.07 & 1.23 & 17 & 1.81 & 1.79 \\
\hline 7 & 1.11 & 1.02 & 17 & 1.27 & 1.22 & 9 & 1.34 & 1.07 & 17 & 1.27 & 1.22 \\
\hline Avg & 1.16 & 1.43 & & 1.60 & 2.16 & & 1.72 & 1.71 & & 1.63 & 1.94 \\
\hline
\end{tabular}

(a) Including all models

(b) Excluding models 9, 14 and 21 
Table 5. EDYT-20: Best models using the MSE and SED criteria

\begin{tabular}{|r|r|r|r|r|r|r|r|r|r|r|r|}
\hline \multirow{2}{*}{$\begin{array}{c}\text { Tri- } \\
\text { al }\end{array}$} & \multicolumn{3}{|c|}{ IB-R } & \multicolumn{4}{|c|}{ MSE } & \multicolumn{3}{c|}{ SED (a) } & \multicolumn{3}{c|}{ SED (b) } \\
\cline { 2 - 12 } & $\begin{array}{r}\text { SED } \\
\text {-RE }\end{array}$ & $\begin{array}{c}\text { MSE } \\
-R E\end{array}$ & $\begin{array}{c}\text { Mo- } \\
\text { del }\end{array}$ & $\begin{array}{c}\text { SED } \\
-R E\end{array}$ & $\begin{array}{c}\text { MSE } \\
-R E\end{array}$ & $\begin{array}{c}\text { Mo- } \\
\text { del }\end{array}$ & $\begin{array}{c}\text { SED } \\
-R E\end{array}$ & $\begin{array}{c}\text { MSE } \\
-R E\end{array}$ & $\begin{array}{c}\text { Mo- } \\
\text { del }\end{array}$ & $\begin{array}{c}\text { SED } \\
-R E\end{array}$ & $\begin{array}{c}\text { MSE } \\
-R E\end{array}$ \\
\hline \hline 1 & 1.32 & 1.22 & 12 & 1.49 & 1.56 & 12 & 1.49 & 1.56 & 12 & 1.49 & 1.56 \\
\hline 2 & 0.69 & 0.75 & 15 & 1.27 & 1.27 & 14 & 1.53 & 0.96 & 5 & 1.29 & 1.18 \\
\hline 3 & 1.12 & 1.05 & 12 & 2.69 & 2.60 & 12 & 2.69 & 2.60 & 12 & 2.69 & 2.60 \\
\hline 4 & 1.00 & 1.04 & 17 & 1.02 & 1.07 & 14 & 1.05 & 0.71 & 17 & 1.02 & 1.07 \\
\hline 5 & 1.02 & 0.93 & 17 & 1.23 & 1.23 & 21 & 1.42 & 1.00 & 12 & 1.25 & 1.17 \\
\hline 6 & 0.95 & 0.99 & 17 & 0.98 & 1.02 & 1 & 1.00 & 1.00 & 1 & 1.00 & 1.00 \\
\hline \hline Avg & 1.02 & 1.00 & & 1.45 & 1.46 & & 1.53 & 1.31 & & 1.46 & 1.43 \\
\hline
\end{tabular}

(a) Including all models

(b) Excluding models 9, 14 and 21 
Table 6. Mean MSE-RE and SED-RE of the best three more frequent models for the MSE, SED(a), and SED(b) criterion.

\begin{tabular}{|c|c|c|c|c|c|}
\hline \multirow{2}{*}{ Criteria } & Ranking & Model & Frequency & SED-RE & MSE-RE \\
\hline \multirow{3}{*}{ MSE } & 1 & 17 & 14 & 1.70 & 1.64 \\
\cline { 2 - 6 } & 2 & 12 & 5 & 1.71 & 2.60 \\
\cline { 2 - 6 } & 3 & 15 & 4 & 1.32 & 1.37 \\
\hline \multirow{3}{*}{ SED(a) } & 1 & 14 & 16 & 1.55 & 1.09 \\
\cline { 2 - 6 } & 2 & 17 & 9 & 2.03 & 2.23 \\
\cline { 2 - 6 } & 3 & 12 & 3 & 1.89 & 1.85 \\
\hline \multirow{3}{*}{ SED(b) } & 1 & 17 & 21 & 1.75 & 1.79 \\
\hline & 2 & 12 & 5 & 1.70 & 1.64 \\
\hline
\end{tabular}




\section{Frequency}

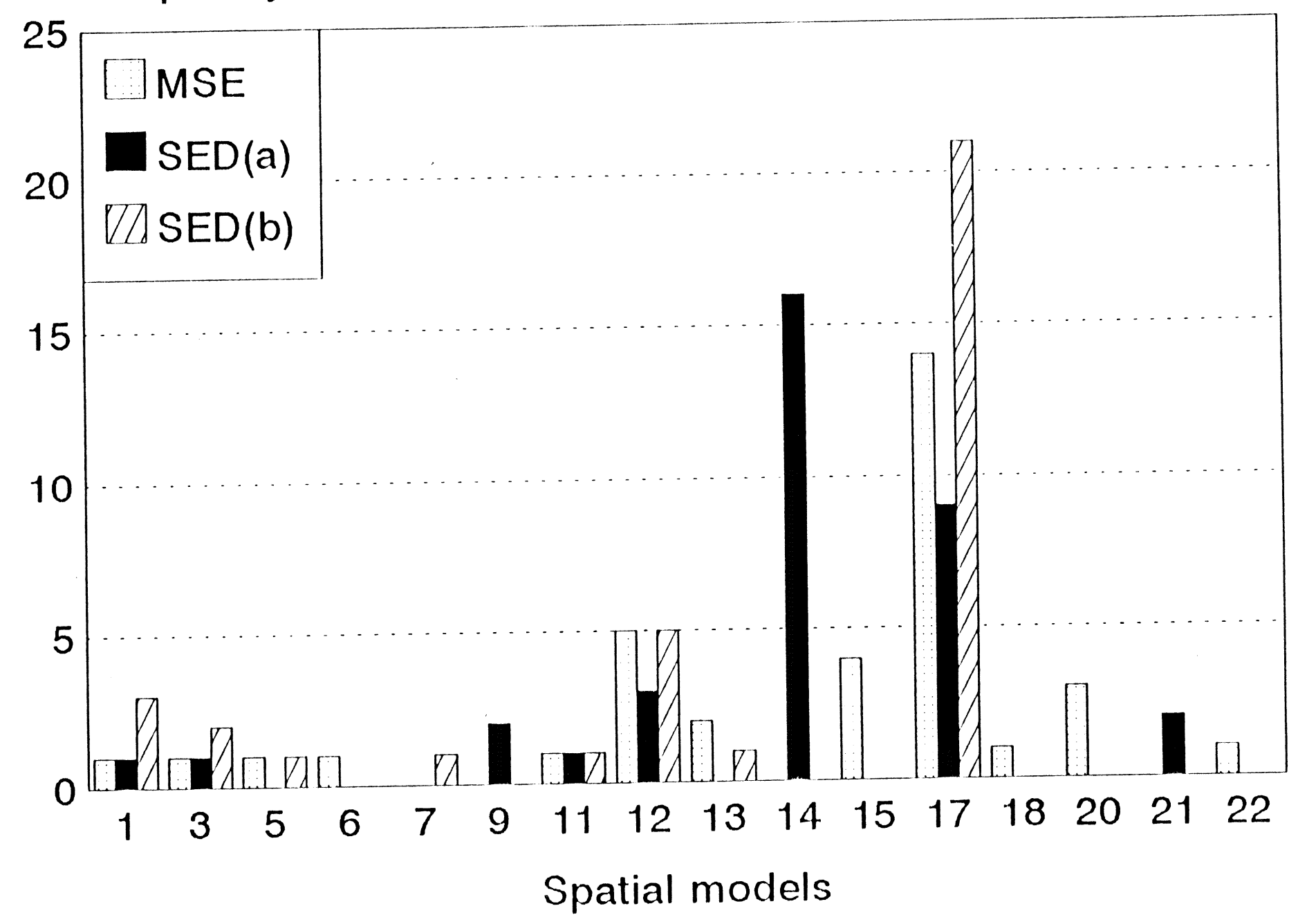

Fig. 1. Best models based on MSE and SEDs 